\title{
Luciane Ruschel
} Nascimento Garcez ${ }^{1}$ Sandra Makowiecky²

\section{Elke Otte Hülse: narrativas ancestrais e técnicas expandidas na tapeçaria ${ }^{3}$}

Elke Otte Hülse: ancestral narratives and expanded tapestry techniques

Elke Otte Hülse : recits ancestraux et techniques elargies de tapisserie 


\section{Resumo}

As tapeçarias compreendem e podem ser consideradas como uma forma narrativa de arte ancestral, que tem na história grande importância, e no contemporâneo, encontramos artistas que extrapolam e expandem a técnica, problematizando conceitos e questões pertinentes a esta. Elke Otte Hülse, artista catarinense com trânsito internacional, rompe fronteiras geográficas e fronteiras do desconhecimento desta técnica secular e é apresentada junto a um breve histórico da tapeçaria, com o intuito de apresentar sua atualidade.

Palavras-chave: Elke Otte Hülse; Tapeçaria; História da arte; História da tapeçaria; Narrativa.

\section{Abstract}

Tapestries comprise and can be considered as a narrative form of ancestral art, which is of great importance in history, and in the contemporary, we find artists who extrapolate and expand the technique, problematizing concepts and issues pertinent to it. Elke Otte Hülse, a Santa Catarina artist with international traffic, breaks geographical boundaries and boundaries of ignorance of this secular technique and is presented along with a brief history of tapestry, with the purpose of presenting its actuality..

Keywords: Elke Otte Hülse; Tapestry; Art History; History of the tapestry; Narrative.

\section{Résumé}

Les tapisseries constituent et peuvent être considérées comme une forme narrative d'art ancestral, qui revêt une grande importance dans l'histoire et, dans le monde contemporain, nous trouvons des artistes qui extrapolent et développent la technique, en problématisant les concepts et les questions qui le concernent. Elke Otte Hülse, artiste de Santa Catarina au trafic international, brise les frontières géographiques et les limites de l'ignorance de cette technique laïque et est présentée avec une brève histoire de la tapisserie, afin de présenter son actualité.

Mots-clés: Elke Otte Hülse ; Tapisserie ; Histoire de l'art ; Histoire de la tapisserie ; Narrative.

ISSN: 2175-2346

1 Atualmente é pesquisadora e pós-doutoranda pela Universidade do Estado de Santa Catarina (UDESC), Centro de Artes (PPGAV-CEART). Membro da Associação Brasileira de Críticos de Arte Seção Brasil Aica Unesco - ABCA. Membro da Associação Internacional de Críticos de Arte- AICA. Membro da Associação Nacional de Pesquisadores de Artes Plásticas - ANPAP. Link para Lattes: http://lattes.cnpq.br/8041551261651027
ORCID: https://orcid.org/0000-0002-7659-3362 E-mail: lucianegarcez@gmail.com

2 Atualmente é professora Titular da Universidade do Estado de Santa Catarina (UDESC) - graduação, mestrado e doutorado em Artes Visuais do Centro de Artes PPGAV-CEART). Membro da Associação Brasileira de Críticos de Arte Seção Brasil Aica Unesco - ABCA. Membro da Associação Internacional 


\section{Situando a tapeçaria}

Em algumas áreas do conhecimento, encontramos menos referências bibliográficas do que em outras, sobretudo na Academia, quando tratamos de técnicas de tradição mais longeva. A tapeçaria, sendo uma técnica antiga que se localiza no limiar entre a arte, o design e o artesanato, se enquadra na arte contemporânea como forma de resistência. Durante séculos, tapetes foram responsáveis por contar histórias, guardar a cultura de povos e trazer conforto visual e sensorial para as casas. O breve histórico da tapeçaria é mobilizado nesta narrativa, visando apresentar esta ancestralidade que insiste e persiste no contemporâneo. E porque subsistem, nos intrigam por vezes mais do que trabalhos que fazem parte de um status quo do contemporâneo, como as novas mídias, instalações, performances mais midiáticas. A tapeçaria, essa arte do silêncio e da paciência, que rompe fronteiras em sua forma de trabalhar junto, nos chama. Como podemos situar a tapeçaria na arte contemporânea? Qual seu papel na história da arte? Temos esta tradição tapeceira na arte brasileira? Estas são algumas questões que estão sendo discutidas neste artigo, onde a artista Elke Otte Hülse (1961) é abordada a partir de um pensamento que abrange a tapeçaria como meio de expressão artística, extrapolando qualquer possibilidade de limitação a uma técnica artesanal. Abordamos a tapeçaria como um método de criação que vem sendo passado de geração em geração através dos tempos, contando histórias, a partir da questão do narrador de Walter Benjamin, pois que até pouco tempo atrás, era desta forma que a técnica era passada adiante. Pensamos a tapeçaria, ponto a ponto, como uma forma de narrar uma história. Segundo Hülse (2009), em sua dissertação de mestrado sobre a tapeçaria, em vários períodos da história, era executada em ateliês com diversos tapeceiros atuando juntos, onde os mais jovens aprendiam com os mais experientes através da imitação e da tradição oral. Por ser um processo lento que pode levar até meses para se completar, a tapeçaria voltou à tona recentemente com a retomada dos trabalhos artesanais como forma terapêtica e antagônica à evolução tecnológica avançada. Muitos estão indo além nesse processo de reconexão com a ancestralidade manual e se baseiam nas formas da natureza, por exemplo, para criar tapeçarias com visual que mimetizam campos, florestas e outras "paisagens".

Sobre as técnicas de bordado e tapeçaria, as categorias de materialização e do sentido háptico das imagens, e das narrativas míticas e femininas sobre a tecelagem são tratadas à luz de autores como Hans Belting, Charles Sanders Peirce, Lúcia Santaella, Michel Serres, Mircea Eliade, Michelle Perrot, Walter Benjamin e Nelly Novaes Coelho, entre outros. Todavia, não iremos tratar de forma aprofundada tal questão neste artigo. As entrevistas e outros artistas que são mencionados neste texto, aparecem como forma de estabelecer comparações e evidenciar procedimentos usuais na tapeçaria.

de Críticos de Arte- AICA. Membro do Comitê Brasileiro de História da Arte - CBHA. Membro da Associação Nacional de Pesquisadores de Artes Plásticas - ANPAP. Membro do Instituto Histórico e Geográfico de SC - IHGSC. Vice-Presidente ANPAP - Associação Nacional de Pesquisadores em Artes Plásticas no biênio 2007-2008. Coordenadora do Museu da Escola Catarinen-

se (MESC-UDESC)

Link para Lattes: http://lattes.cnpq.br/7738155362538526 ORCID: http://orcid.org/0000-0002-9132-3643.

Email: sandra.makowiecky@gmail.com 


\section{Tapeçaria e história}

Tratamos neste artigo de uma revisão europeia da história da tapeçaria, todavia, em outros estudos, pretendemos abordar o cenário da história dessa prática no Brasil, mesmo que os dados sejam escassos. Citamos apenas como referência e enriquecimento do texto, o trabalho de Alessandra Marinho Bouty (2018), sobre os bordados de Matizes Dumont.

A tapeçaria tem sua história ligada ao desenvolvimento das culturas mais ancestrais. Há milhares de anos, antes do período que conhecemos como Antigo Egito, ela já estava em desenvolvimento. E durante muito tempo foi um artefato bastante importante nas trocas comerciais, o que possibilitou que as técnicas também migrassem: as cores, os pontos, o tipo de lã ou tecido, nós, cores e formas, cada detalhe destes pode contar um pouco sobre a história e os locais de produção da peça. Como forma de aquecer, separar cômodos, proteger, ornar, esteve presente ao longo da história. As técnicas foram se desenvolvendo conforme as tecnologias assim proporcionavam, mas alguns preceitos básicos se mantiveram. Ponto a ponto, a tapeçaria é uma das formas de criação mais caras e que consome mais tempo em sua fatura.

Tapeçaria é um tipo de arte têxtil, onde a imagem é reproduzida sobre ou no tecido. Um exemplo é a técnica dos liços, onde os desenhos são produzidos em tear simultaneamente ao tecido, enquanto que no bordado, o desenho é feito com agulhas sobre uma tela/tecido pré-existente, como a talagarça.

Tanto os egípcios quanto os Incas enrolavam seus mortos em certos tipos de tapeçarias. Na Grécia antiga, edifícios importantes, incluindo o Parthenon, tinham paredes cobertas por elas. No entanto, foram os tecelões medievais franceses que difundiram e deram novos sentidos à técnica. No final do medievo, por volta do século XIII, a igreja católica reconheceu o valor da tapeçaria por ver nela um instrumento para contar a história de Cristo, uma ferramenta para ilustrar os textos bíblicos. Poucas chegaram até nós, nem o material, muito suscetível ao clima e intempéries, nem as técnicas de conservação colaboraram neste sentido. $O$ mais antigo conjunto existente é o "Apocalipse de São João", seis tapeçarias de parede de 5,5 metros de altura, totalizando 143,5 metros de comprimento que foram tecidos de 1375 a $1379 \mathrm{em}$ Paris. Esta região foi o centro de produção até a Guerra dos Cem Anos (1337 - 1453), que fez com que os tecelões fugissem para o norte via Arras para a Flandres (atual Bélgica e norte da França) e deslocassem o polo produtivo 4 .

Neste período, as tapeçarias se configuraram como símbolos de status e prestígio na aristocracia europeia. Além do uso prático, isolando as paredes dos caste-

3 Este texto parte de um artigo mais amplo, onde também está situada a história da tapeçaria a partir da fatura da artista catarinense Elke Otte Hülse, porém expande e contextualiza a história da Bauhaus e seus desdobramentos no contemporâneo. As autoras estão divulgando a produção de Hülse em revistas acadêmicas visando atualizar a prática da tapeçaria, bem como dar visibilidade à artista catarinense, que além de figurar em importantes mostras internacionais, foi selecionada no ano de 2109 para compor um panorama da arte produzida em Santa Catarina, na 14 Bienal Internacional de Curitiba - Polo SC.

4 Disponível em: https://www.britannica.com/art/tapestry. Acesso em mar.2019 
los, aquecendo, dividindo os ambientes e provendo certa privacidade em torno das camas, as tapeçarias também eram espaços de ornamentação e contavam histórias. Muitas vezes seu motivo era encomendado especificamente para este fim: registrar um feito, deixar alguma narrativa imortalizada em imagens. Compreendemos por narrativas pictóricas o que compreendemos por narrativas ficcionais, ou seja, podem ser entendidas também como imagens ficcionais, como produções que contam histórias com uma leitura particular de seus autores/artistas, como fatos narrados, romanceados, explorados a partir de uma linha de condução, assim sendo, se constituem em transcrições pictóricas de uma história narrada. A tapeçaria é aqui entendida como uma narrativa pictórica.

Os motivos mais comuns na ldade Média eram retirados dos textos sagrados, as narrativas bíblicas contavam a vida de Cristo, dos santos e mártires, e também do Velho Testamento, mas algumas exploraram mitos e fábulas, alegorias e costumes pagãos, outras ainda contavam histórias de conquistas, guerras e cenas do cotidiano. Esse crescimento da arte da tapeçaria coincidiu com a era da arte românica e gótica, períodos de grande devoção religiosa, quando arquitetura, escultura e vitrais também foram aproveitados pela Igreja para ilustrar histórias bíblicas para congregações analfabetas.

Foi em meados do século XIV que a tradição da Europa Ocidental se estabeleceu firmemente. Naquela época, os centros de produção de tapeçaria mais desenvolvidos estavam localizados em Paris e na Flandres. Exemplos preservados do século XIV são raros, no entanto, e os mais importantes foram criados por tecelões parisienses.

No século XV, cerca de 15.000 tecelões e outros artesãos trabalhavam apenas nos centros de tapeçaria do Vale do Loire. Utilizando teares verticais e horizontais, e uma gama de no máximo 20 cores, os tecelões medievais produziram imagens de histórias religiosas do Antigo e do Novo Testamento e, a partir de 1500, cenas seculares de batalha, reis e nobres. No século XV não era raro o monarca levar seu pintor oficial para registrar o que se passava nas batalhas, sempre exaltando a figura do monarca, e depois transformando a narrativa em grandes tapeçarias a serem expostas em seus castelos. Por vezes, ao serem invadidos os castelos, tapeçarias eram levadas, o que incorria em ter que modificar os tamanhos das peças para se fecharem janelas ou aberturas de tamanhos diferentes. Por esta razão, várias foram cortadas ou costuradas umas nas outras. Desta forma algumas histórias se misturavam, ou eram interrompidas.

A trajetória da tapeçaria sofreu reveses após a Revolução Francesa (1789), pois as mudanças sociais decorrentes prejudicaram o mercado de tais manufaturas, sendo estas consideradas muito elitistas para que seu uso fosse incentivado. Mas os fios de prata e ouro usados nas tapeçarias também pesaram nesta decisão, e em 1797 quase 200 peças foram queimadas e os metais recuperados.

No início do século XIX foi inventado o tear mecânico em Flandres, o que permitiu que as tapeçarias se tornassem mais acessíveis, retomando e popularizando seu uso. Ao final deste mesmo século, a manufatura francesa Gobelin chegou a produzir uma paleta de cores de 14.000 tons, inédito na época, o que trouxe 
possibilidades antes impensadas na hora de criar as imagens e retratar figuras e cenas com maior realismo tonal. Mas foi o movimento inicialmente inglês do Arts and Crafts que renovou a tapeçaria e deu frutos ainda hoje importantes. Ao retomar diversas técnicas deixadas de lado pela Revolução Industrial, William Morris e seus companheiros deram novos ares e possibilidades à técnica, que de certa forma havia perdido seu estatuto. Morris pesquisou os tecelões franceses, desenvolveu um tear e aprendeu sozinho a tecer a partir de um manual francês do século XVIII. Junto aos colegas do movimento, criaram desenhos para tapeçarias inspirados em estilos e técnicas medievais. Os tecelões da Morris and Co. obtiveram sucesso comercial, divulgaram a técnica brilhantemente, e influenciaram (e influenciam) artistas até hoje.

Segundo Maria Isabel Gradim (2018), o artista francês Jean Lurçat (1892-1966) foi fundamental no processo de revalorização da tapeçaria no séc. XX, além de iniciar um movimento de renovação da técnica, trouxe artistas como Braque e Picasso para criarem desenhos a serem transformados em tapeçarias. Enquanto o uso de obras têxteis de grande porte era comum em ambientes públicos e oficiais, a fim de atestar o poder político e material de quem as possuía, Lurçat deslocou esta noção e as conferiu lugar nas galerias e exposições, dando à tapeçaria um novo estatuto, 0 de "obra de arte" 5 .

\section{Dizer e ver: tapeçaria como narrativa e discurso}

Apesar das dificuldades de preservação destas peças, algumas tapeçarias importantes chegaram até nós. Por vezes estragadas, necessitando de restauros, limpeza e atenção, mas sem perder a beleza e grandiosidade iniciais, e mais importante, deixando ao contemporâneo registros históricos inestimáveis, pois além da história contada, técnica e materiais nos dizem muito deste passado revisitado.

A "Tapeçaria de Bayeux" (fig.1) é uma das mais conhecidas, e não é à toa. Apesar de ser mundialmente conhecida como tapeçaria, é na verdade um bordado, com fios de lã sobre tecido de linho. Consiste em 75 cenas, mede 50 centímetros de altura e quase 70 metros de comprimento. Representa uma batalha pelo trono da Inglaterra entre William, o duque da Normandia, e Harold, o conde de Wessex. Culminando na Batalha de Hastings em 1066, quando William invadiu e conquistou com sucesso a Inglaterra, tornando-se o primeiro rei normando desta (também conhecido como William, o Conquistador). O final da tapeçaria agora está faltando, mas provavelmente mostrou sua coroação, de acordo com Kristine Tanton. Segundo esta autora e historiadora, a "Tapeçaria de Bayeux" é considerada por muitos como uma crônica, apesar de haverem elementos que fazem parte da história da batalha; mas as imagens contam um momento particular da história da Inglaterra, e também pode ser considerada como importante fonte visual de pesquisa a têxteis dos séculos XI e XII que não sobreviveram ao seu tempo.

A atenção dos artífices a certos detalhes fornece fontes importantes para o

5 Disponível em: https://tapestry-art.com/tapestries-history/. Acesso em fev.2019 
cotidiano da vida europeia no século XI, além de mostrarem objetos que não existem mais, mostram cenas gastronômicas e modos de preparo de refeições em acampamentos militares, exemplos de armaduras usadas no período, estratégias de preparação para batalhas.

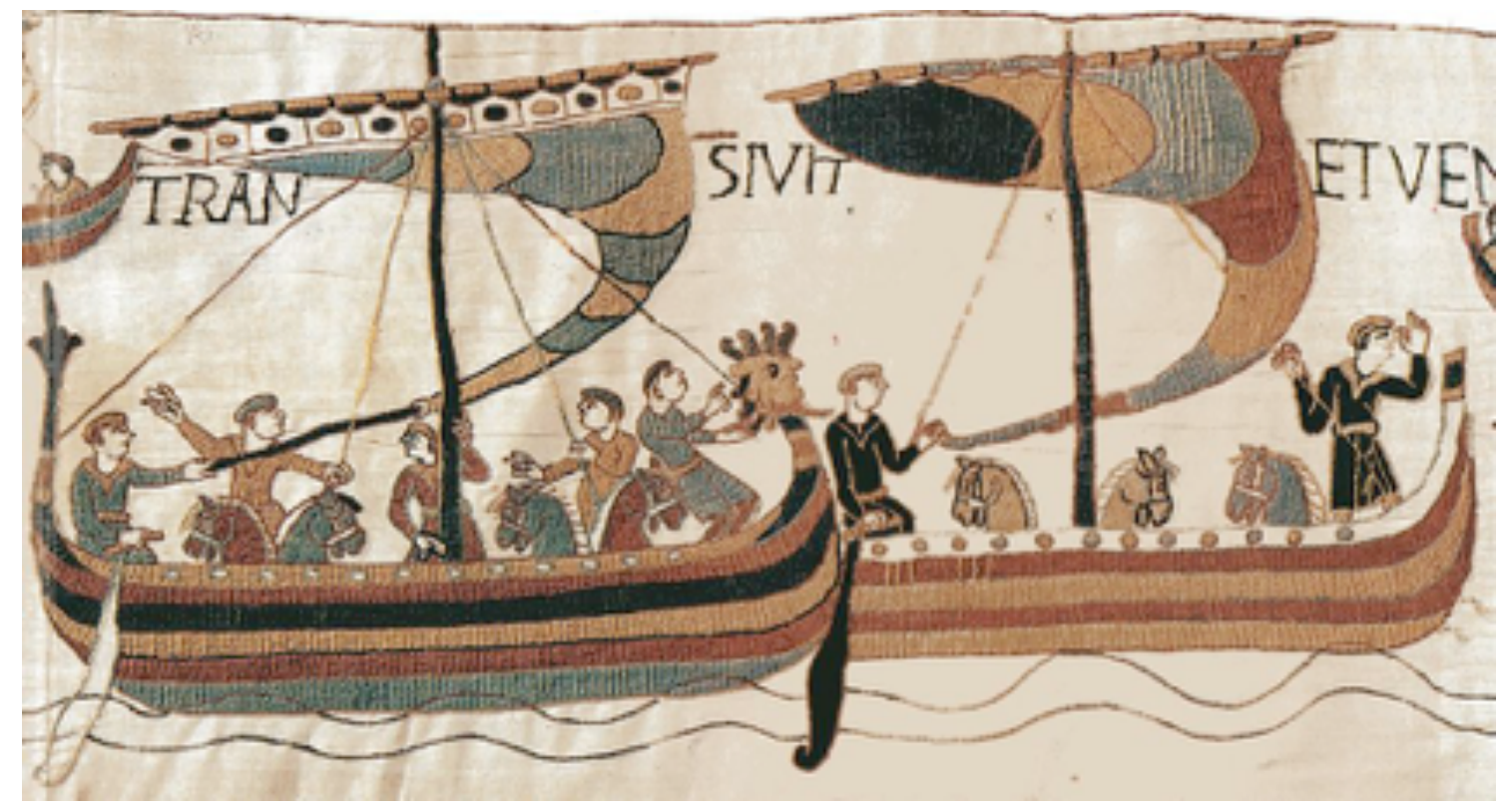

Figura1. Tapeçaria de Bayeux (aprox. 1070)

Normandos com cavalos em barcos, cruzando para a Inglaterra, em preparação para a batalha (detalhe).

Tecido de linho bordado com fios de lã. 0,50 X 70 m. Museu Bayeux

Fonte: https://www.khanacademy.org/humanities/ap-art-history/early-europe-and-colonial-americas/medieval-europe-islamic-world/a/ bayeux-tapestry

A "Tapeçaria de Bayeux" provavelmente foi feita em Canterbury por volta de 1070. Com base em algumas evidências, os historiadores da arte acreditam que o patrono foi "Odo", bispo de Bayeux, meio irmão de William, duque da Normandia. Outra evidência é o tom favorável aos normandos que podemos observar nas imagens da obra, apresentando assim o ponto de vista deles, e não dos ingleses. Odo pode ser visto em várias cenas, como a inscrição ODO EPISCOPUS (abreviado como "EPS" na fig. 2), onde diz: "Aqui, Odo o Bispo, e sua equipe (baculum) incentiva jovens guerreiros", embora ele seja mencionado apenas brevemente em fontes textuais. No final da Idade Média, a tapeçaria foi exposta na Catedral de Bayeux, que foi construída por Odo em 1077, mas seu tamanho e o assunto tratado, não sendo um exemplar religioso, sugere que ela possa ter sido planejada para estar pendurada em alguma sala do castelo do bispo, e não sua igreja.

De acordo com Tanton, serve como um artefato medieval que opera como arte, crônica, propaganda política e evidência visual de objetos mundanos do século XI, todos em escala monumental. Grande exemplo de uma arte que diz ao mundo como se vivia em sua época. 


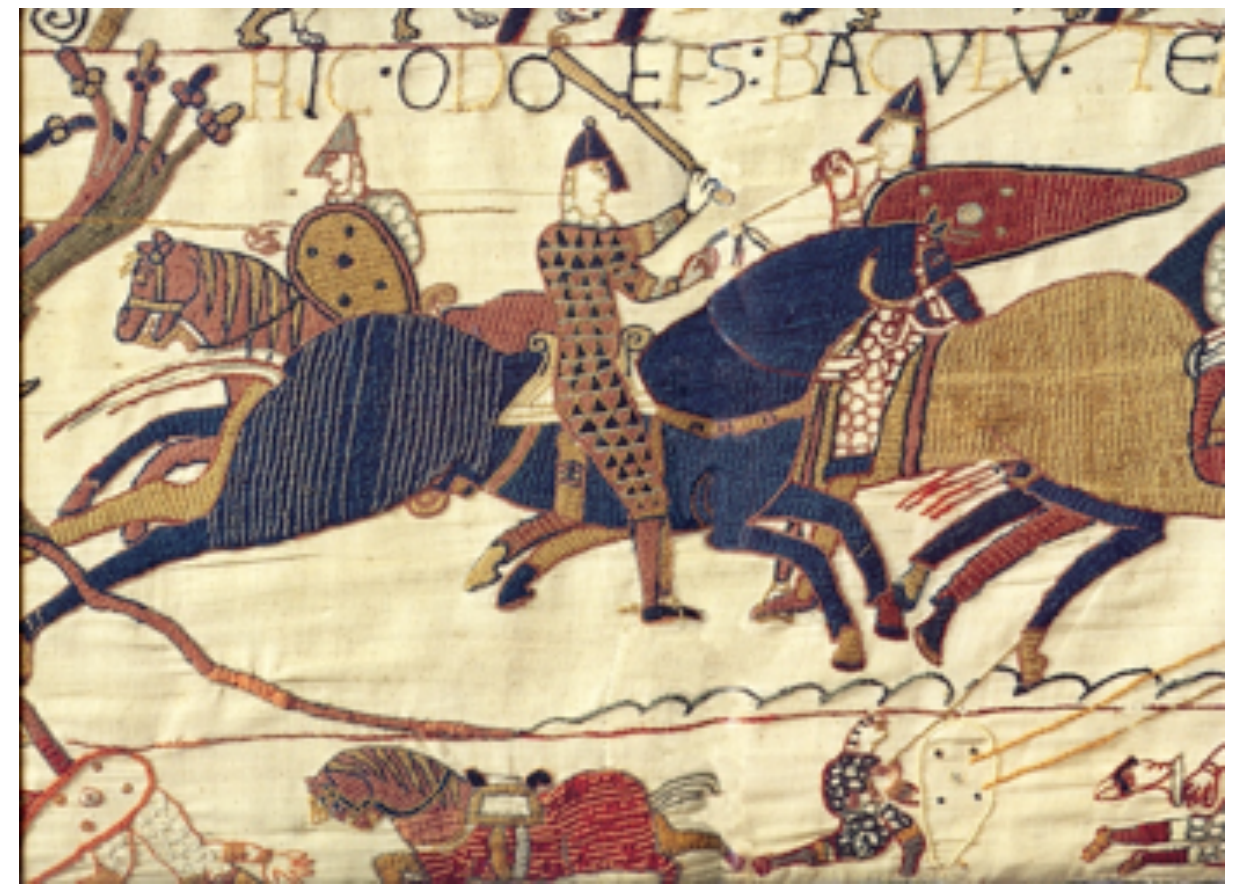

Figura 2. Tapeçaria de Bayeux (aprox. 1070).

Tecido de linho bordado com fios de lã. 0,50 X 70 m. Museu Bayeux

Fonte: https://www.khanacademy.org/humanities/ap-art-history/early-europe-and-colonial-americas/medieval-europe-islamic-world/a/bayeux-tapestry

Outro grande exemplo de narrativa em tapeçaria é a "Tapeçaria do Apocalipse de São João", já mencionada (fig. 3), conjunto de 6 cenas medindo aproximadamente 4,5 metros de altura, em que cada cena contém aproximadamente 14 momentos desenvolvidos a partir de um personagem introdutório, totalizando de cerca de 100 metros de comprimento, remanescentes dos 143 metros originais, e cobrindo uma área e $850 \mathrm{~m} 2$. Este é sem dúvida o conjunto de tapeçarias medievais mais significativo do mundo e se encontra na Galeria do Apocalipse, no Castelo de Angers, na França.

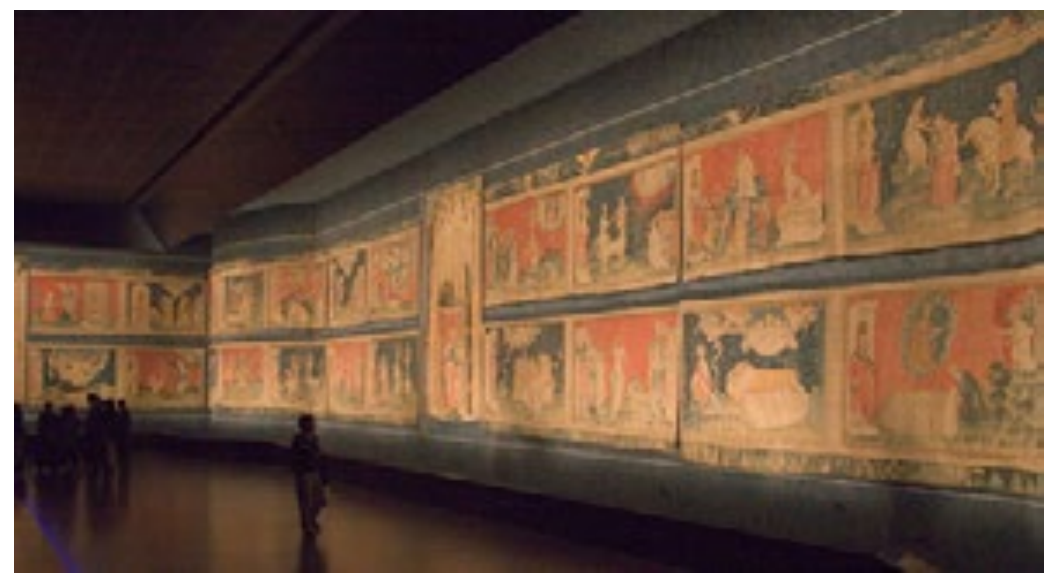

Figura 3. Tapeçaria do Apocalipse $(1377$ - 1382) Tapeçaria. 4,5 X 100m. Castelo de Angers, França.

Fonte: http://projects.leadr.msu.edu/medievalart/exhibits/show/salvation-narratives/object-4-apocalypse-tapestry

Tapeçaria inicialmente ornamental, foi criada em uma forma narrativa que ilus- 
tra o livro do Apocalipse, no Evangelho de João e inspirada nas iluminuras do século XII. Estilo medieval tardio, já esboça certo realismo, tecida com cores fortes e de alto contraste, na técnica do alto-liço, cuja urdidura é composta por fios não tingidos, servindo de base ao desenho dos cartões. As imagens de fundo das cenas arquitetônicas são feitas em uma única perspectiva e têm uma qualidade tridimensional. Junções e nós são escondidos, detalhe que atesta a alta qualidade da manufatura, assim como a exata reprodução da imagem no lado oposto da tapeçaria ${ }^{6}$, sendo conhecida como uma peça "sem avesso".

Cada cena na tapeçaria tem São João, geralmente dentro de uma pequena cabana, anotando suas Revelações, ocasionalmente cobrindo o rosto com horror no que vê ou gesticulando com preocupação. Poderíamos dizer que é um meta texto, como o artista continua mostrando, Esta não é a história do apocalipse - esta é a história de São João sobre como ele recebeu e escreveu as revelações do apocalipse. É uma narrativa sobre uma narrativa. Também ilustra simbolicamente os problemas sociais do período, como a fome e a peste.

Em 1938, o tapeceiro Jean Lurçat visita pela primeira vez o conjunto no palácio episcopal, e foi o ponto de partida para a criação de sua série de tapeçarias "Le Chant du Monde", que hoje faz parte de um museu dedicado a este artista ${ }^{8}$, localizado em Angers, no antigo hospital de São João (fig.4). Lurçat desenvolveu os desenhos entre 1957 e 59, sendo 10 painéis de diferentes tamanhos confeccionados em diferentes ateliês (HÜLSE, 2013), totalizando 80 metros de comprimento. Retratam as alegrias e tristezas da existência humana, em uma visão simbolista do séc. XX, e são uma homenagem às tapeçarias do Apocalipse. Iniciam com um tributo ao apocalipse nuclear de Hiroshima, e continuam até a "Conquista do espaço". Ressonâncias contemporâneas de criações atemporais.

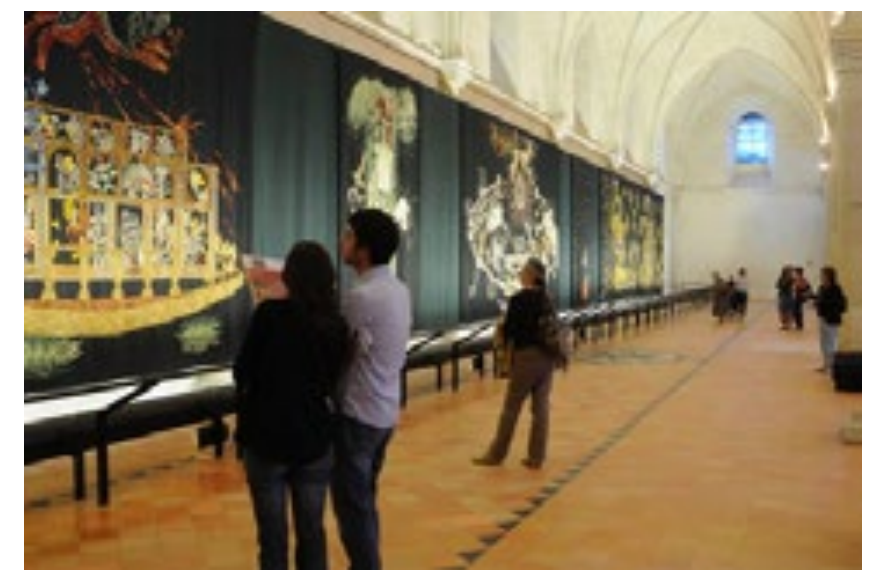

Figura 4. Jean Lurçat. Le Chant du Monde (1957-66) $342 \mathrm{~m} 2$. Musée Jean Lurçat et de la Tapisserie, Angers, França. ${ }^{10}$

6 Disponivel em: http://www.chateau-angers.fr/Explorer/La-Tapisserie-de-I-Apocalypse. Acesso em fev.2019.

7 Idem.

8 Musée Jean Lurçat et de la Tapisserie.

9 Fundado em 1174, pelo rei Henry II, é o mais antigo hospital não-militar da França.

10 Fonte: http://musees.angers.fr/langues-etrangeres/english/musee-jean-lurcat-et-de-la-tapisserie-contemporaine/the-collections/le-chant-du-monde/index.html 
A série de tapeçarias "A Dama e o Unicórnio", do fim do séc. XV, início do XVI, apesar de a um primeiro momento não nos parecer uma narrativa - não está nos contando nenhum grande feito, nem situação especial que remonte à história -, não nos deixemos enganar: é uma narrativa simbólica sobre nossa condição humana. Composição de seis peças: tato, paladar, olfato, audição e visão são as cinco representações nesta série. E a sexta? Nomeada de acordo com a inscrição na própria imagem, "À mon seul désir" (fig.5), inspirou diversas lendas e teorias ao longo de sua história, incluindo significados que abordariam o conceito medieval de amor cortês, onde a dama estaria exercendo o livre arbítrio, renunciando aos prazeres mundanos, ou o chamado 6은 sentido, que seria uma prerrogativa feminina.

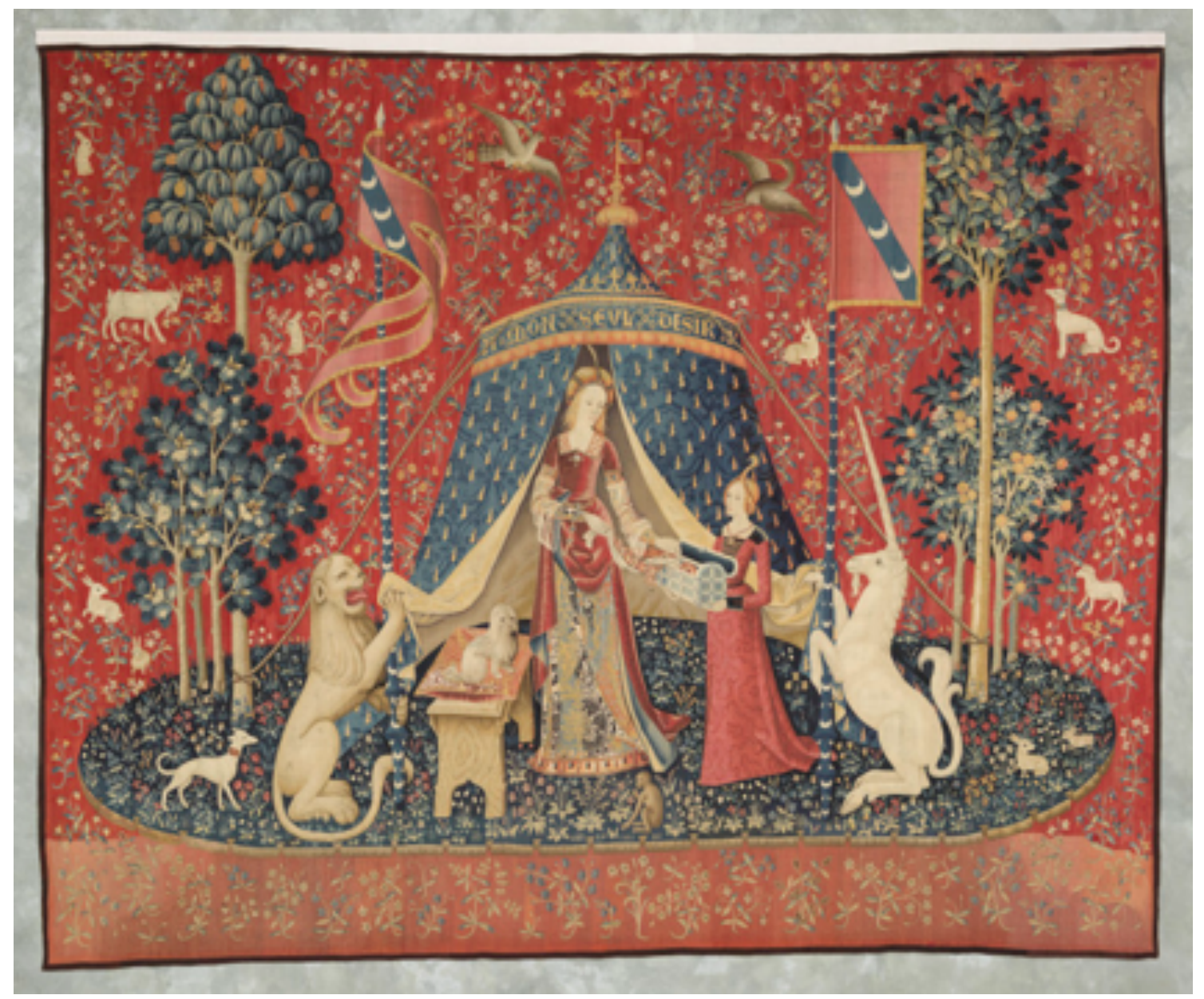

Figura 5. A Dama e o Unicórnio: O meu único desejo. Tapeçaria. 3,76 X 4,73m. Museu de Cluny, França.

Fonte: https://www.musee-moyenage.fr/collection/oeuvre/la-dame-a-la-licorne.html

De dimensões aproximadas, as cinco tapeçarias que abordam os nossos sentidos têm em torno 3,1 X 3,3m cada, sendo a sexta a maior, com 3,76 X 4,73m. Esta série é considerada uma obra prima do início da Renascença francesa, estando ainda hoje no patamar das obras mais reconhecidas nesta área, e sendo referencial teórico 
e imagético a artistas contemporâneos ${ }^{11}$. Interpretada como uma alegoria aos cinco sentidos e ao desejo, é um exemplo da técnica conhecida como millefleur, fundo que repete em cada uma delas, e retoma os mesmos elementos, personagens e animais, destacando-os sobre um fundo irreal e colorido de flores e árvores. Usando cores contrastantes, o azul se destaca sobre o vermelho sangue, predominante nas composições. A jovem, sempre vestida com ricos veludos e brocados, por vezes acompanhada de sua criada, tem como companhia constante o leão e o unicórnio, além de alguns outros pequenos animais esporádicos, e elementos da heráldica, como os brasões, bandeira e flâmula.

Existem muitos estudos e teorias que tentam explicar as origens desta obra; segundo André Arnaud ${ }^{12}$, seria uma narrativa sobre a vida de Maria Tudor na França, a 3ạ esposa de Luís XII e irmã de Henrique VIII, que foi rainha da França em 1514, tendo sido tecidas na região de Flandres, por Antoine Le Viste, que já havia feito um retrato dela aos 16 anos. Mas ainda não há informações assertivas que nos elucidem a história destas tapeçarias. Seguindo as sucessivas cortes, as tapeçarias teriam sido passadas de geração em geração até chegar ao Castelo de Boussac, no século XVIII. Encontradas em 1841 por Prosper Mèrimée, Inspetor de Monumentos Históricos, e por George Sand (1804-76) ${ }^{13}$, que as evocou em artigos:

Este castelo, muito bem preservado, é um belo monumento da Idade Média, e contém tapeçarias que merecem a atenção e pesquisa de um antiquário. Não sei se algum nativo se deu ao trabalho de descobrir o que é representado ou o que se entende por esse notável trabalho, há muito abandonado aos ratos, manchado por séculos, e que agora consertamos em Aubusson com sucesso (Apud LAURETTE, s/d, s/p).

Seus textos despertaram curiosidades sobre as tapeçarias. A escritora também as mencionou em seu livro "Jeanne", romance de 1844 :

A decoração mais bonita deste salão eram inquestionavelmente estas curiosas tapeçarias enigmáticas que ainda hoje vemos no castelo de Boussac, e que supomos terem sido trazidas do Oriente por Zizime para decorar a torre Bourganeuf, durante seu longo cativeiro. [...] Os figurinos são do final do século XV. Esses quadros manuais são obras-primas e, se não me engano, uma página histórica muito curiosa (Apud LAURETTE, s/d, s/p).

Bastante curioso outro artigo onde Sand escreveu sobre outras duas tapeçarias desta série: "Em oito painéis que preenchem duas grandes salas, vemos o retrato de uma mulher, a mesmo em todos os lugares, obviamente; jovem, magra, longa, loira e bonita; vestida com oito trajes diferentes, todos na moda no final do século XV" (Apud LAURETTE, s/d, s/p). Em 1882, quando o castelo foi vendido, haviam somente seis peças.

\footnotetext{
$11 \mathrm{https} / / /$ www.musee-moyenage.fr/collection/oeuvre/la-dame-a-la-licorne.html. Acesso em abr.2019.

12 André ARNAUD, que trabalhou no atelier Robert FOUR, em AUBUSSON, publicou sua pesquisa sobre estas tapeçarias na revista Galerie des Arts, $n^{\circ} 209$, de outubro de 1981, edição especial "Magia da tapeçaria". Mais informações em: http://dame-licorne.pagesperso-orange.fr/VERSION\%20LONGUE/00-\%20sommaire\%20version\%20longue.htm. Acesso em abr. 2019.

13 Pseudônimo de Amandine Aurore Lucile Dupin, baronesa de Dudevant, aclamada romancista e memorialista, considerada uma das maiores escritoras francesas.
} 
Certa correspondência de Merrimé traz uma informação que corrobora à ideia de que talvez houvessem outras duas tapeçarias: "Haviam outras mais bonitas, me disse o prefeito, mas o antigo dono do castelo - pertencente hoje à cidade - um Conde de Carbonière, as cortou para cobrir charretes e torná-las tapetes" (Apud LAURET$\mathrm{TE}, \mathrm{s} / \mathrm{d}, \mathrm{s} / \mathrm{p}$ ). Persiste o mistério, mas a beleza e a história destas tapeçarias continuam a influenciar e inspirar artistas e teóricos dos mais diversos locais, tempos e campos de atuação.

\section{Elke Hülse: história da arte e a tapeçaria como forma de contar a história}

Hülse é artista, tapeceira, educadora e pesquisadora - uma das poucas, senão única no Brasil, a pesquisar e publicar academicamente sobre a tapeçaria contemporânea, ao mesmo tempo em que as produz. Possui graduação e mestrado em artes visuais, sendo a ênfase em Teoria e História da Arte, campo que a permite estudar e divulgar um pouco sobre esta técnica tão resignada em nosso país. Em uma cultura que vê a tapeçaria como uma técnica artesanal, esquecendo, ou não se importando em buscar seu passado e sua importância no desenrolar da história da arte, e mais importante, suas infinitas possibilidades de expressão artística, plenamente inseridas no cenário tão complexo da arte contemporânea. Elke Otte Hülse tem então um papel fundamental de produção e divulgação da tapeçaria como arte, e o vem desenrolando com primazia, sendo hoje uma das mais expressivas e reconhecidas artistas brasileiras a trabalhar com esta técnica, uma vez que vem representando nosso país em eventos artísticos, acadêmicos e culturais ao redor do mundo.

Mas a artista não vê a tapeçaria somente como uma técnica, ela a encara como uma forma de contar histórias, sejam elas reflexos de um tempo passado, visto ser uma teórica da história da arte que não se furta a buscar e desenvolver suas referências, sejam elas alinhadas ao contemporâneo, reflexos de vivências percebidas que na arte temos a oportunidade de problematizar de formas mais sutis, poéticas e sofisticadas.

Uma série de tapeçarias de Hülse que vamos abordar se chama "Girls Everywhere Girls". A ideia foi esboçada em 2013, quando esta fez uma tapeçaria para uma exposição na Peter Gray Gallery, na Universidade de Guadalajara em Puerto Vallarta no México, e cuja temática era "Borders" (Fronteiras). A partir daí a ideia foi se consolidando e nasceu a série mencionada, tendo como ponto conceitual uma proposta teórica, lançada pela curadora da 16 ${ }^{\text {a }}$ Trienal Internacional da Tapeçaria, que acontecerá no Central Museum of Textiles em Łódź, Polônia, em 2019, Marta Kowalewska, onde ela convida artistas a pensarem as fronteiras a partir da tapeçaria como meio técnico de produção artística. "Breaching Borders" ("Violar fronteiras") é a temática explorada nesta exposição, onde problemas muito atuais serão abordados nas mais diversas poéticas. 
Em matéria no catálogo das artes ${ }^{14}$ sobre tapeçaria na Polônia, o texto fala deste país com forte tradição nesta técnica, e conta que a riqueza das diversas técnicas de arte popular inspirou um grupo de artistas, que em 1901 fundou a associação "Arte Utilitária Polonesa", unindo os melhores artistas e entusiastas dessa categoria de arte. O objetivo da associação era a renovação do artesanato polonês. Os intelectuais atuavam à semelhança de John Ruskin e William Morris, criadores da corrente "Arts \& Crafts" na Inglaterra, e propagadores da ideia do resgate da importância do trabalho manual. Os estudos sobre tapeçaria, sendo incluídos no programa de escolas superiores, davam o prestígio devido à arte a esta modalidade, tratada antes como artesanato e não como expressão artística. Muitos artistas e pedagogos contribuíram para a criação da "Escola Polonesa de Tapeçaria" através da sua influência em algumas gerações de artistas que, junto com eles, começaram a expor suas obras em mostras nacionais e internacionais. Nos anos 60 e 70, o êxito dos artistas poloneses confirmaram a sua primazia na área da arte da fibra.

A influência da tapeçaria polonesa foi grande na atividade de artistas brasileiros, que nos anos 70 e 80 fizeram estágios na Polônia, o que provocou o desenvolvimento da arte de Zoravia Betiol, de Porto Alegre, e de Carlos Obino, do Rio de Janeiro. Na Trienal de Lódz, o Brasil foi representado pela composição "The Way Life Is" de Shirley Paes Leme, que estudou em Tucson, Arizona, onde a Seção de Tapeçaria é dirigida pela profa. Gayle Wimmer, formada pela Academia de Belas Artes de Varsóvia. A pro$\mathrm{f}$. Eleonora Plutynska tinha um dito preferido: "O mais importante é a continuação, porque esta é a ordem das coisas"15, o que tem a ver com a questão da narrativa já expressa. De certa forma, este jeito de trabalhar em grupos aponta uma necessidade de reflexão sobre as novas relações de geopolítica e imaginário, de entremundos e a condição fronteiriça da arte e do ser humano contemporâneo. Essa continuação no desenvolvimento da arte mundial de tecelagem é sedimentada pelas confrontações internacionais em Lódz, Budapeste, Kyoto e outras numerosas cidades da Europa e de ambas as Américas. A arte da fibra liga, com a linha da amizade, artistas e nações.

Segundo Elke, esta série de tapeçarias (figs. 6, 7 e 8), "Girls everywhere Girls" (7 peças de $75 \times 50 \mathrm{~cm}$ até o momento), é uma pesquisa sobre faces de meninas de diferentes etnias e culturas. Para esta artista, violar fronteiras significa aceitar diferenças étnicas. As sutilezas de cada rosto, suas cores, formas, feições, características que reforçam suas origens, mostram a importância de valorizar cada grupo étnico ${ }^{16}$. As tapeçarias são costuradas em cima de vestidinhos de meninas, mencionando a prática de artistas e artesãos coptas, que costuravam tapeçarias em suas roupas como forma de adorno. Elke Otte Hülse foi selecionada no ano de 2109, por chamada pública, para participar da 14 Bienal Internacional de Curitiba - Polo SC, com três obras desta série.

14 OWIDZKA, Jolanta. Tapeçaria na Polônia. 2007. Disponivel em: https://www.catalogodasartes.com.br/historia_arte/zzel. Acesso em fev. 2019. 15 Idem.

16 Em entrevista com as autoras em 12 de abril de 2019. 


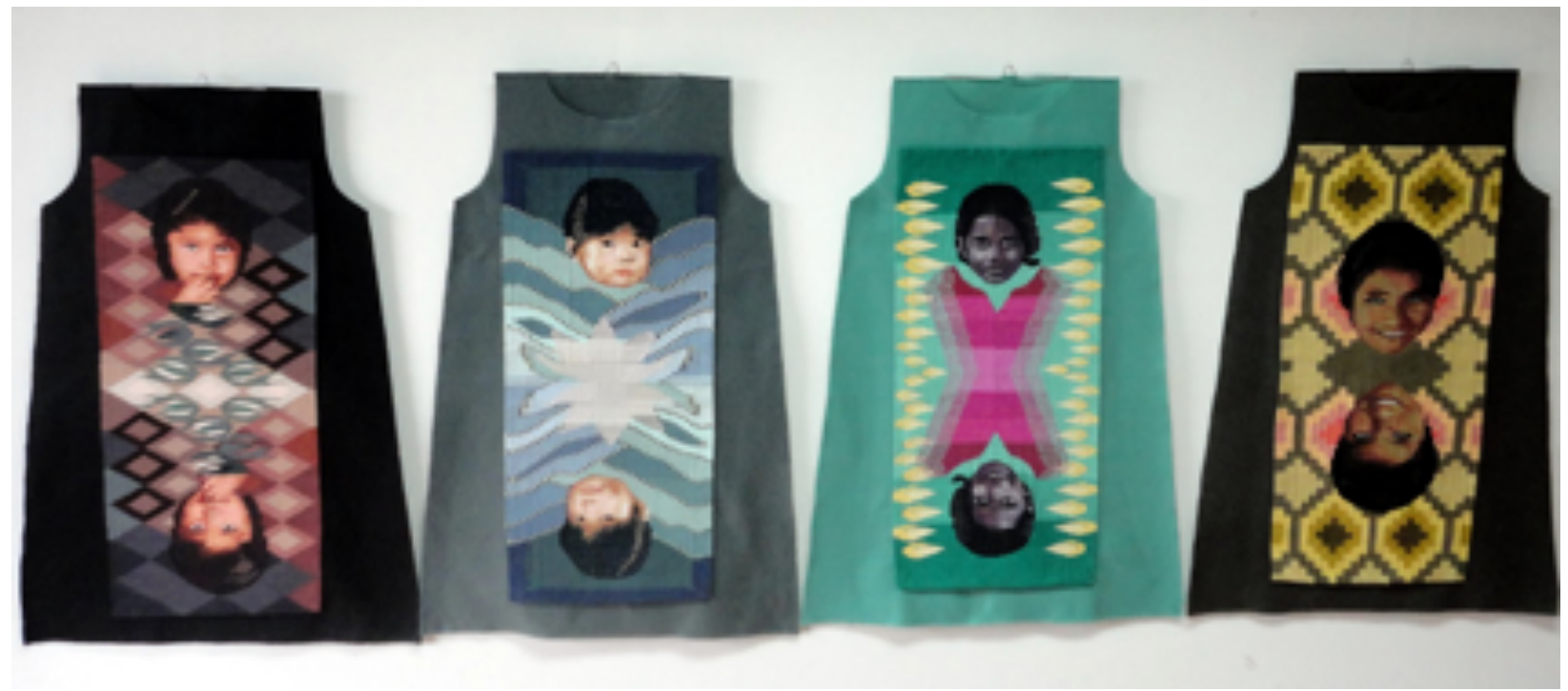

Figura 6. Elke Hülse. Girls everywhere Girls. 2018.

Tapeçaria. 76 X 50cm cada.

Fonte: imagem cedida pela artista.

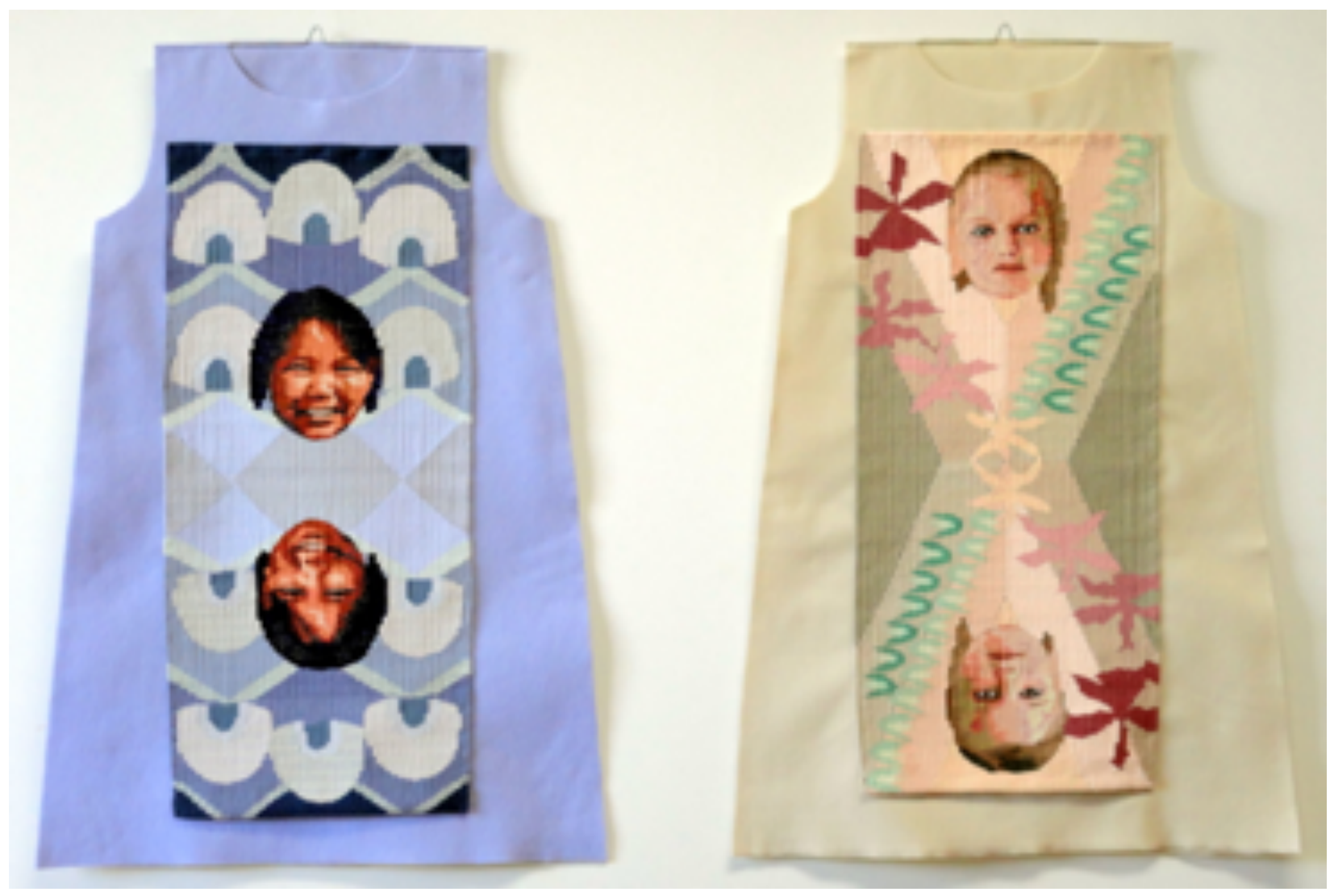

Figura 7. Elke Hülse. Girls everywhere Girls. 2019.

Tapeçaria. 76 X 50cm cada.

Fonte: imagem cedida pela artista. 


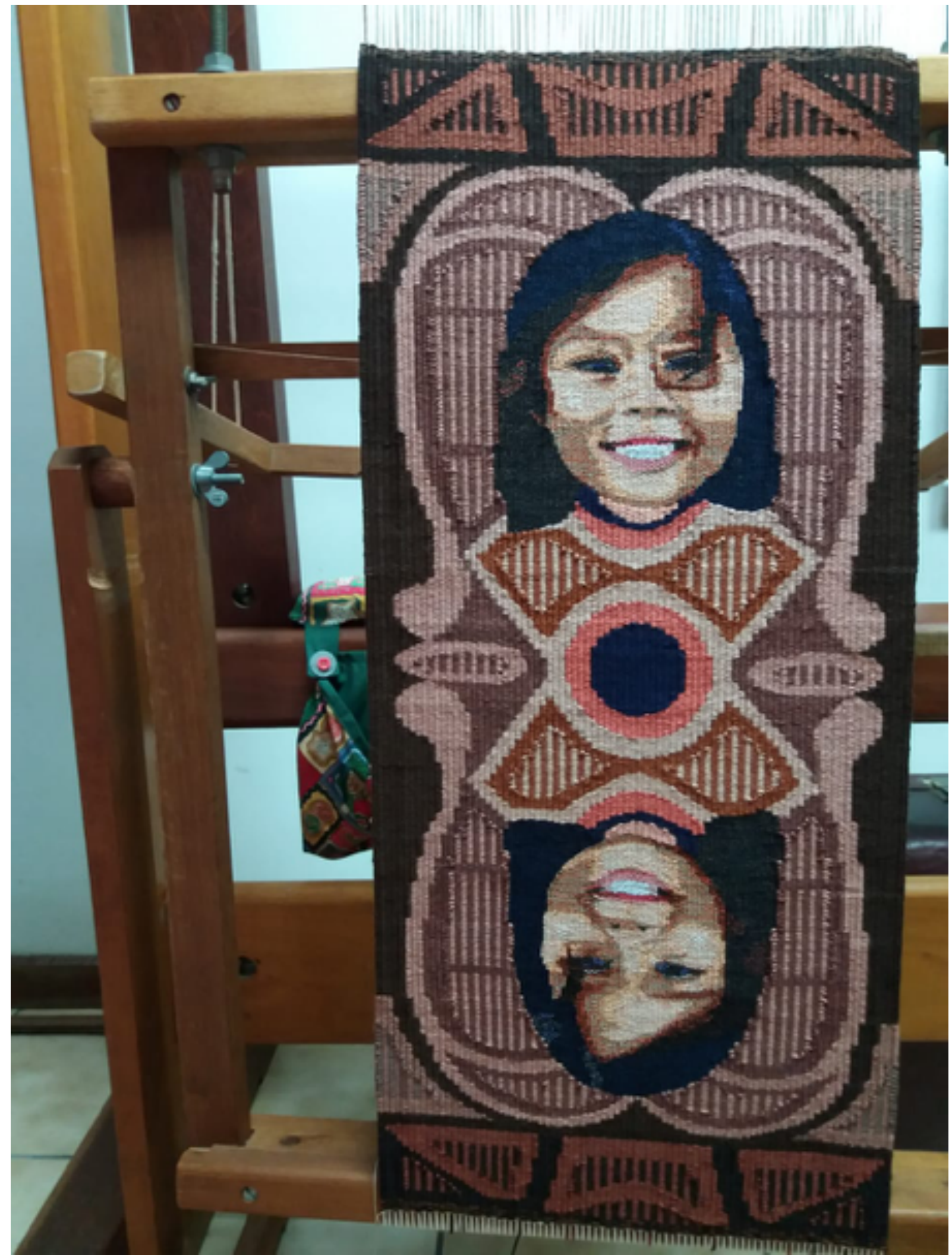

Figura 8. Elke Hülse. Girls everywhere Girls (em processo de acabamento). 2019.

Tapeçaria. 76 X 50cm cada.

Fonte: imagem cedida pela artista. 
Podemos também mencionar o projeto "Dress a Girl Around the World"17, ONG americana fundada em 2009, cujo objetivo é costurar vestidos para serem entregues a meninas de populações carentes ao redor do mundo. Com a justificativa que estas meninas estariam recebendo um vestido feito especialmente para elas, não uma segunda mão como doação de caridade, mas algo especial, um presente, conferindo carinho e dignidade a estas crianças. Cada vestido deve ser costurado de acordo com os moldes propostos, sendo que cada detalhe é bem pensado e importante para o resultado final. As meninas que os recebem, estão antes de tudo recebendo atenção, e tendo sua situação de vulnerabilidade discutida. O projeto dá voz a estas organizações que tentam cuidar destas meninas, independentemente de sua cor, raça ou proveniência, também desmontando fronteiras.

Cada criança retratada nos conta uma história, não sua história de vida, privada e única, mas a história que sua cultura revela, tradições, costumes, mitos e lendas associados a cada etnia pela artista representada.

A figura 9 mostra uma obra chamada "Kinder Glauben" (em português pode ser traduzido como "crença infantil") e é uma tapeçaria de 2016, que tem seu início em um texto proposto pelo edital de Kárpit, e a série de tapeçarias do "Apocalipse" (vista acima neste texto), cujas imagens remetem às ilustrações dos livros infantis alemães que a artista tinha em sua infância. $O$ ponto de partida desta peça foi uma imagem retirada da Internet que mostra duas crianças, uma negra e uma branca, as duas se olham e se tocam com muita delicadeza. Hülse montou sua composição a partir de 6 pentágonos, onde cada um conta uma história e conversa com o outro. Segundo a artista,

Sem entrar no mérito do conteúdo das mesmas, enfatizo na minha composição a apresentação em forma de quadros e reduzido uso de cores. Ao me apropriar da imagem das duas crianças na internet, logo consegui traduzi-la mentalmente para a linguagem da tapeçaria. Esse raciocínio facilita na escoIha de materiais, técnicas e resoluções de espaços no conjunto da obra. Cada pentágono conta uma história e ao mesmo tempo todos estão interligados. Cada dois rostos, mesmo em pentágonos distintos, se tocam pelo tato e pelo olhar. $\mathrm{Na}$ execução de cada dois pentágonos, existem linguagens específicas onde a escolha de materiais determina a conversação ${ }^{18}$. 


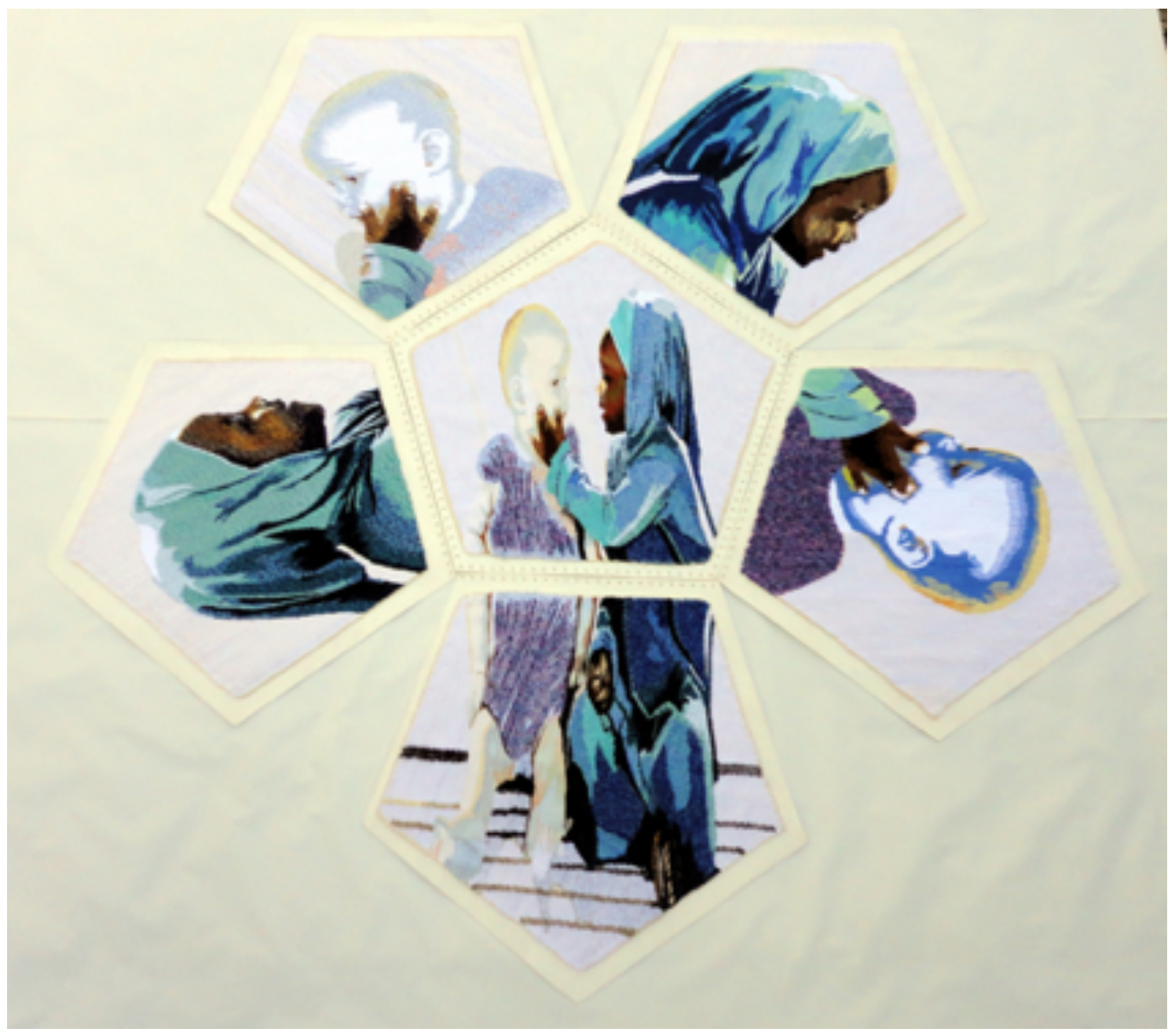

Figura 9. Elke Hülse. Kinder Glauben (Children Believe). 2016. Tapeçaria. $2,5 \times 2,15 \mathrm{~m}$

Fonte: imagem cedida pela artista.

Algodão, restos de tecido e fios diversos, texturas variadas marcam os detalhes desta tapeçaria. O pentágono central, que mostra os rostos das duas crianças, é encimado por outros 4, como uma auréola a dar a devida importância à cena que se passa no centro. O pentágono inferior retrata os corpos das crianças. Segundo a artista, o material escolhido para cada pentágono é importante para a sensação háptica resultante, sendo que nos pentágonos centrais, materiais clássicos da tapeçaria foram misturados a retalhos de tecidos industriais cortados em tiras, assim como fios feitos de garrafas plásticas recicladas.

Em cada pentágono a artista trabalha com diversos tons de brancos, dando a estas crianças uma luz que remete a diversas manifestações da história da arte, invocando o sagrado da imagem, especialmente pela aura colocada acima da imagem principal. Segundo Hülse, esta luz invoca também o eterno retorno da imagem ${ }^{19}$. 0 
título se refere à épica cruzada infantil da Idade Média ${ }^{20}$, quando crianças tentaram cruzar os Alpes em direção a Jerusalém.

Essa determinação infantil baseada nos sentidos como audição, visão, olfato, paladar e tato leva a acreditar que essa tapeçaria também tem um objetivo, qual seja, a sustentabilidade global. Talvez muito mais do que o reaproveitamento de materiais na confecção da tapeçaria, o tema e a sua mensagem são o acontecimento e o caminho para a sustentabilidade global. Crianças que trocam afagos e olhares de forma tão singela, sincera e espontânea, evidenciam uma fenomenologia do tato e do olhar (HÜLSE Apud ANTONELLO, 2017, s/p).

Esta obra esteve presente em uma exposição individual de Elke Hülse no Museu de Arte de Blumenau (MAB), em 2017. Em 2018 a obra foi selecionada em um edital para figurar na 10th Bienal de arte têxtil "From Lausanne to Beijing", na China. Evento organizado pela universidade de Tsinghua, pelo Fiber Art Institute, da Universidade de Arte Pública na Academia Nacional de Pintura da China, e pelo Fiber Art Committee, da Associação Chinesa de Arts and Crafts, sendo o trabalho de Hülse de grande representatividade para nosso país, onde 1375 trabalhos, provenientes de 45 países foram submetidos, e apenas 175 obras, de 183 artistas, representantes de 40 countries foram selecionados para a exposição ${ }^{21}$. Estes dados nos dão uma métrica sobre a importância do trabalho desta artista em representar o Brasil nesta arte tão pouco reconhecida em nosso país. "Kinder Glauben" também foi aceito no evento brasileiro “FIBRA - 1a Bienal de Arte Têxtil 2019", em Porto Alegre, RS, cujo tema é "Sustentabilidade: Um Olhar Sobre as Suas Diversas Possibilidades", e que contempla aproximadamente 100 trabalhos selecionados por edital, contando com a participação de artistas de diferentes regiões do Brasil22.

Atualmente Elke Hülse está desenvolvendo um trabalho em parceria com outros dois artistas tecelões, onde irão transformar pinturas da artista Rivane Neuenschwander para a linguagem da tapeçaria.

Em sua dissertação de mestrado, denominada "As tramas dos tapeceiros narradores: técnica e criação" (HÜLSE, 2009), a artista já indica uma função que considera primordial: a narrativa. Na história da cultura escrita registra-se a interpretação das práticas sociais de escrever e de ler. Há também a representação que os autores nos dão das relações que estabelecem com seus cadernos ou cadernetas. A modernidade traz a emergência da cultura escrita, que registra muitos atos da experiência humana, mas a tapeçaria, por seu turno, busca também práticas sociais de contatos. Gilles Deleuze em "Imagem-tempo" (1990) nos remete à função fabuladora, onde é possível reencontrar o elo entre a vida e a ficção, que se daria nas narrativas simulantes. Para que haja narrativa é necessário que haja também um contador de estória e uma estória. O contador de estória é o narrador, no caso, nossa artista, nossos tapeceiros. A narrativa está presente em todos os tempos, em todos os lugares, em todas as

20 http://museudeartedeblumenau.blogspot.com/2017/03/

21 https://www.textile-forum-blog.org/2018/11/10th-from-lausanne-to-beijing-exhibition/

22 https://www.rogerlerina.com.br/post/10558/porto-alegre-recebe-a-fibra-1-bienal-de-arte-textil 
sociedades, começa com a própria história da humanidade, é fruto do narrador ou possui em comum com outras narrativas uma estrutura acessivel à análise. Os artistas mencionados neste artigo nos presenteiam com narrativas plásticas que ilustram histórias por meio de transcrições pictóricas livres em simbólicas alegorias. Entendemos a alegoria como uma representação pictórica que tem como função transmitir um significado outro, dando à imagem uma conotação simbólica, que precisa de uma interpretação mais ampla e aprofundada para ser desvendada. Diferente de símbolo que já tem sua imagem mais rapidamente decodificada e compreendida. Na mencionada dissertação, a artista incluiu um item denominado: "O Narrador o e mestre tapeceiro". Neste, descreve que:

em vários períodos da história a figura do tapeceiro sempre foi associada aos homens, cabendo às mulheres da família o apoio no urdimento, na preparação dos fios da trama e nos arremates. Hoje, nos vários continentes onde a tapeçaria acontece, muitas mulheres, geralmente com mais de trinta anos, exercem a atividade. Nos Estados Unidos da América existe a preocupação de trazer aprendizes jovens aos ateliês para tomarem gosto pela arte da tapeçaria. A figura apresentada por Walter Benjamin aparece aí, porque o mestre tapeceiro repassa aos mais jovens sua experiência e conhecimento na condição de narrador. Não adianta nada o jovem tapeceiro ter acesso a bons livros técnicos e ao exercício da atividade, só isso dificilmente vai envolver e criar vínculos. Mas quando o mestre tapeceiro intercala entre as atividades práticas, narrativas de práticas de ateliê, fatos acontecidos ao longo da história, aí sim existem grandes chances de se criar um novo tapeceiro. (HÜLSE, 2009, p. 49-50).

Para Walter Benjamin, em clássico texto, o aprendiz aprendia através da "[...] experiência que passa de pessoa a pessoa a fonte a que recorrem todos os narradores" (1996, p. 198), salientando ainda que "O grande narrador tem sempre suas raízes no povo, principalmente nas camadas artesanais" (p. 214). E que "O aprendiz [...] é livre para interpretar a história como quiser, e com isso [...] atinge uma amplitude que não existe na informação" (p. 203).

Ao unir narrativas e fronteiras para falar da obra de Elke Hülse, nos ocorre que a ideia de fronteira já não pertence só ao território, à geografia política. O release do anúncio da 14a Bienal de Curitiba, cuja temática central é denominada "Fronteiras em aberto", distribuído para a imprensa em 02/04/2019 e que posteriormente será divulgado na página oficial do evento diz:

Há tempos que o conceito de fronteiras que se expandiu conceitualmente e faz parte de um universo maior de questões mais abrangentes e, sobretudo, mais transversais. Já tem um imaginário plural que toca aspectos de naturezas encontradas. Longe, portanto, da física comensurada, tranquilizadora, de uns limites geográficos que respondem a uma narrativa temática, e mais perto das distorções significativas de índole social, tecnológica, cognitiva, epocal. Ainda mais em nosso tempo cheio de mudanças e transformações de signo diverso (com a concorrência das novas coordenadas espaço-temporais, a globalização, a pós-história, a tecnologização do mundo, a crise ambiental, a procura de novas cosmologias etc.), o que desloca o sentido das antigas semânticas, fixadas unidimensionalmente em um sentido único. 
Assim, podemos dizer que mesmo com algumas resistências por parte de cena contemporânea, que a tapeçaria sempre foi vanguarda, pois já sabem faz bastante tempo, conforme demonstrado neste artigo, que há fronteiras reais e também invisíveis. Que a fronteira pode ser várias coisas ao mesmo tempo e que a arte sempre foi um espaço de fronteira, um hiato entre o reino da linguagem e o da realidade, um estado limiar, de natureza flutuante, não fixa. A arte consiste nessa dupla vigília, na cisão atávica da representação da linguagem. Essa possibilidade de nomear o habitat desde a linguagem, ainda de religar-se como um novo lugar denota que a arte exerce essa dupla questão de entender que dizer e ver pode ser visto como um problema para pensar a obra de arte. As tapeçarias atuando neste limite de narrativas ancestrais e técnicas expandidas estão a nos dizer isso.

\section{Referências}

BENJAMIN, Walter. O narrador - Considerações sobre a obra Nicolai Leskov. IN: BENJAMIN, Walter. Obras Escolhidas: Magia e Técnica, Arte e Política. São Paulo: Brasiliense, 1996, p.197-221.

BOUTY, Alessandra Marinho. Letras por um Fio: A tradução intersemiótica do conto A Moça Tecelã, de Marina Colasanti, nos bordados de Matizes Dumont / Alessandra Marinho Bouty. - 2018. 173 f.: il. color. Dissertação (mestrado) - Universidade Federal do Ceará, Instituto de cultura e Arte, Programa de Pós-Graduação em Comunicação, Fortaleza, 2018. Orientação: Profa. Dra. Gabriela Frota Reinaldo.

BOXALL, Ian. The Apocalypse Unveiled: Reflections on The Reception History of Revelation. In: The Expository Times. 125 (6): 261-271, 2014.

DELEUZE, Gilles. Imagem-tempo. Cinema 2. São Paulo: Editora Brasiliense, 1990.

GRADIM, Maria Isabel de Souza. Tapeçaria no Brasil nas décadas de 1960 e 1980. USP - Instituto de Estudos Brasileiros. PPG em Culturas e Identidades brasileiras. São Paulo, 2018. Dissertação de mestrado.

HÜLSE, Elke O. As tramas dos tapeceiros narradores: técnica e criação. Florianópolis: UDESC, 2009. Dissertação de Mestrado.

A memória do cartão e a potência da tapeçaria. In: PALÍNDROMO № 9 /2013 - Programa de Pós-Graduação em Artes Visuais - CEART/UDESC.

\section{Webgrafia}

ANTONELLO, Sergio. Exposição Kinder Glauben valoriza a crença infantil no Museu 
de Arte de Blumenau - Artista Elke Hülse faz arte inspirada na linguagem da tapeçaria. In: Fundação Cultural de Blumenau, postada em 02/03/2017, com acesso em 09/04/2019. Disponível em: https://www.blumenau.sc.gov.br/secretarias/fundacao-cultural/fcblu/elke-hulse-faz-arte-inspirada-na-crenca-infantil45 Acesso em jan. 2019

BŁASZCZYK, Dobromiła. THE RENAISSANCE OF TEXTILES. In: Contemporary Lynx. Nov 3, 2018. Disponível em: https://contemporarylynx.co.uk/the-renaissance-of-textiles, com acesso em mar. 2019

CHANT DU MONDE. Disponível em: http://musees.angers.fr/langues-etrangeres/ english/musee-jean-lurcat-et-de-la-tapisserie-contemporaine/the-collections/le-chant-du-monde/index.html. Acesso em mar. 2019

CHATEAU ANGERS. Disponível em: http://www.chateau-angers.fr/Explorer/La-Tapisserie-de-l-Apocalypse. Acesso em jan. 2019

LA TAPISSERIE DE L'APOCALYPSE. Musèe de la Château d'Angers. France 2016. Disponível em: http://www.chateau-angers.fr/Explorer/La-Tapisserie-de-l-Apocalypse. Acesso em mar. 2019

LORETTE, Jacky - Mary Tudor - Suffolk - ... Dame à la Licorne. Sem data. Disponível em: http://dame-licorne.pagesperso-orange.fr/VERSION\%20LONGUE/01-\%20 avant\%20propos.htm. Acesso em abr. 2019

OWIDZKA, Jolanta. Tapeçaria na Polônia. 2007. Disponível em: https://www.catalogodasartes.com.br/historia_arte/zze/. Acesso em fev. 2019

TANTON, Kristine. The Bayeux Tapestry. Artigo publicado por Khan Academy. Disponível em: https://www.khanacademy.org/humanities/ap-art-history/early-europe-and-colonial-americas/medieval-europe-islamic-world/a/bayeux-tapestry >. Acesso em mar. 2019

https://www.musee-moyenage.fr/collection/oeuvre/la-dame-a-la-licorne.html. Acesso em fev. 2019

http://musees.angers.fr/langues-etrangeres/english/musee-jean-lurcat-et-de-la-tapisserie-contemporaine/the-collections/le-chant-du-monde/index.html. Acesso em jan. 2019 